\title{
ORAL CANCER IN NEW SOUTH WALES
}

\section{Murray Walker}

Professor of Oral Pathology, University of Sydney Westmead Centre for Oral Health

This article describes the incidence and mortality associated with oral cancer in NSW. The risk factors associated with the development of oral cancer, and prevention strategies, are also presented.

\section{INCIDENCE}

About two per cent of all new cases of cancer in NSW are oral cancer, of which more than 90 per cent are squamous cell carcinomas (arising from the surface epithelium). In New South Wales in 1995, 582 new cases of oral cancer (lip and oral cavity; International Classification of Diseases-9 140-1, 143-6) were reported, with most occurring on the lower lip and tongue (Table 1). ${ }^{1}$

Oral cancer occurs mainly in middle aged and older people, with 93 per cent of cases reported in people aged 45 years or older. ${ }^{1}$ Men have a higher risk of developing oral cancers than women (Table 1). The life-time risk to age 74 for men varies from one in 286 for developing cancer of the tongue to one in 676 for oropharyngeal cancer. For women, the risk ranges from one in 644 for cancer of the mouth to one in 1816 for cancer of the oropharynx.

In NSW, the incidence of mouth and pharyngeal cancers increased by 27 per cent in men and three per cent in women between the periods $1973-77$ and 1988-92. ${ }^{2}$ Most of the increase occurred in the late 1970s and early 1980 s in parallel with similar trends in Europe and the United States. ${ }^{3}$

Oral cancer particularly affects the socially disadvantaged. ${ }^{4}$ In urban areas of NSW from 1987 to 1991, age-standardised incidence and mortality rates of cancers of the mouth and pharynx in males were significantly higher in groups of lower socioeconomic status. Incidence in females was also significantly higher in the lower socio-economic groups, while the difference in mortality rates was not significant. ${ }^{5}$

\section{MORTALITY}

The risk of dying from oral cancer is low (Table 1). In 1995, 166 people died from oral cancer in NSW, representing 1.5 per cent of all cancer deaths in the state. ${ }^{1}$ More than threequarters of deaths ( 78 per cent) occurred in people aged 60 years or older. ${ }^{1}$

\section{SURVIVAL}

Surviving oral cancer varies significantly depending on the site of the cancer. Today, very few patients die from lip cancer (Table 2), whereas the survival from intra-oral cancer is much lower and only approximately half of the patients with tongue cancer are alive five years after diagnosis (Table 2). The risk of death at five years in those

\section{TABLE 1}

INCIDENCE AND MORTALITY OF ORAL CANCER, NSW 1995

\begin{tabular}{|c|c|c|c|c|c|c|c|c|}
\hline \multirow[t]{2}{*}{ Site } & \multirow[t]{2}{*}{$\begin{array}{l}\text { ICD-9 } \\
\text { code } \neq\end{array}$} & \multicolumn{3}{|c|}{ Number of new cases } & \multicolumn{2}{|c|}{$\begin{array}{l}\text { Age-standardised } \\
\text { incidence rate* }\end{array}$} & \multicolumn{2}{|c|}{$\begin{array}{l}\text { Cumulative risk to } \\
\text { age } 74 \text {, one in... }\end{array}$} \\
\hline & & Male & Female & Total & Male & Female & Male & Female \\
\hline \multicolumn{9}{|l|}{ Incidence } \\
\hline Lip & 140 & 167 & 61 & 228 & 5.6 & 1.6 & 230 & 951 \\
\hline Tongue & 141 & 106 & 33 & 139 & 3.4 & 1.0 & 286 & 1200 \\
\hline Mouth & $143-5$ & 81 & 68 & 149 & 2.6 & 1.9 & 380 & 644 \\
\hline Oropharynx & 146 & 46 & 20 & 66 & 1.5 & 0.6 & 676 & 1816 \\
\hline Oral cancer & $\begin{array}{l}140,141 \\
143-5,146\end{array}$ & 400 & 182 & 582 & $\dagger$ & $\dagger$ & $\dagger$ & $\dagger$ \\
\hline \multicolumn{9}{|l|}{ Mortality } \\
\hline Lip & 140 & 2 & 2 & 4 & 0.1 & 0.1 & 24744 & - \\
\hline Tongue & 141 & 47 & 16 & 63 & 1.5 & 0.4 & 696 & 3661 \\
\hline Mouth & $143-5$ & 34 & 25 & 59 & 1.2 & 0.6 & 1001 & 2134 \\
\hline Oropharynx & 146 & 31 & 9 & 40 & 1.0 & 0.2 & 955 & 4353 \\
\hline Oral cancer & $\begin{array}{l}140,141 \\
143-5,146\end{array}$ & 114 & 52 & 166 & $\dagger$ & $\dagger$ & $\dagger$ & $\dagger$ \\
\hline
\end{tabular}




\section{TABLE 2}

FIVE-YEAR RELATIVE SURVIVAL RATE FOR CANCER OF THE LIP ANDTONGUE, NSW, 1980-95

\begin{tabular}{|lcccc|}
\hline Sex & \multicolumn{2}{c}{ Lip } & \multicolumn{2}{c|}{ Tongue } \\
& $\begin{array}{c}\text { Number of } \\
\text { cancers }\end{array}$ & $\begin{array}{c}\text { Five-year relative } \\
\text { survival (\%) }\end{array}$ & $\begin{array}{c}\text { Number of } \\
\text { cancers }\end{array}$ & $\begin{array}{c}\text { Five-year relative } \\
\text { survival (\%) }\end{array}$ \\
\hline Males & 2546 & 96.2 & 1246 & 46.9 \\
Females & 712 & 91.4 & 557 & 58.1 \\
Total & 3258 & 95.2 & 1803 & 50.4 \\
\hline
\end{tabular}

Source: NSW Cancer Registry Cancer Control Information Centre. ${ }^{6}$

with cancer of the tongue that had spread to the lymph nodes in the neck at the time of diagnosis, was more than twice that for patients with localised disease. When distant metastases were identified, the risk of death at five years was more than four times that for localised disease. ${ }^{6}$

In approximately half (46 per cent) of patients with intraoral cancer, the disease had already spread to the lymph nodes in the neck at the time of presentation. ${ }^{6,7}$ There were significant delays in patients presenting for treatment, perhaps due to the absence of symptoms such as pain or dysphagia. There may also be delays in reaching the diagnosis by general medical or dental practitioners. However, the advanced stage of the cancers at presentation contributes to the only moderate survival rate. When patients are referred to specialists, biopsy and appropriate management are usually initiated quickly.

\section{RISK FACTORS}

\section{Ultraviolet light}

The excess of cancers of the lower lip, particularly in AngloCeltic immigrants to this country who work outdoors (for example in agriculture and fishing), is thought to be due to exposure to sunlight. Smoking tobacco can increase this risk.

\section{Tobacco and alcohol}

Tobacco smoking and drinking hazardous or harmful amounts of alcohol (in excess of four units [drinks] a day for men and two units a day for women) are major risk factors for oral cancer, particularly in combination. ${ }^{8}$

\section{Potentially malignant epithelial lesions}

Mouth cancers may evolve from potentially malignant white or red epithelial mucosal patches (leukoplakias and erythroplakias). There is no information on the prevalence of these lesions in Australia or on their rate of malignant change. Overseas studies have shown malignant transformation to squamous cell carcinoma in four to six per cent of leukoplakias followed in a large series of patients over a mean observation period of up to 9.8 years. ${ }^{9-11}$ However, some 15 per cent of leukoplakias with premalignant changes in biopsies (dysplastic lesions) regress spontaneously. ${ }^{12}$

Other conditions also predispose to cancer of the mouth.
These include oral lichen planus (a chronic inflammatory eruption of unknown origin); ${ }^{13}$ oral discoid lupus erythematosus (a localised inflammatory disorder of skin or oral mucosa, possibly auto-immune in nature) $;{ }^{14}$ and oral submucous fibrosis (found in people using betel, characterised by deposits of fibrous tissue in oral mucosa). ${ }^{15}$

\section{Betel}

The use of betel (areca nut) quid with tobacco is associated with eight to 15 times the relative risk of oral cancer in the Indian subcontinent, ${ }^{16}$ and the use of betel quid without tobacco but chewed with lime in Papua New Guinea carries one to four times the relative risk. ${ }^{17}$ These substances are on sale in NSW. The extent of their use is unknown, but likely to be low; however, it may be higher in certain ethnic groups.

\section{Other factors}

Other factors that may predispose individuals to develop oral cancer include oncogenic types of the human papilloma virus, trauma from the teeth or dentures, syphilis, or dental sepsis.

\section{PROTECTIVE FACTORS}

\section{Dietary factors}

Including fruit and green-leafed vegetables in the diet, and normal iron status, seem to protect against oral cancer. The value of individual micronutrients such as vitamins $\mathrm{A}$ and $\mathrm{C}$ has not been confirmed. ${ }^{18,19}$

\section{CONTROL OF ORAL CANCER}

\section{Primary prevention}

Primary prevention has been estimated to be the most cost-effective method of preventing oral cancer. ${ }^{20} \mathrm{Up}$ to three-quarters of oral cancers could be prevented by avoiding environmental factors, notably the consumption of tobacco and excess alcohol. ${ }^{8,21-23}$ Health education about tobacco has been shown to reduce the incidence of leukoplakia. ${ }^{24}$

Recently, 65 people attending the public dental clinic at Westmead Hospital were surveyed. Ninety-one per cent reported knowing nothing about oral cancer and 38 per cent had one or more of the major risk factors for developing 
oral malignancy (for example, tobacco smoking). These findings suggest that oral health professionals need to work in partnership with other health professionals to reduce cigarette smoking and to support primary prevention strategies to promote responsible alcohol intake.

The National Health and Medical Research Council (NH\&MRC) advises that primary health care providers should enquire about their patients' use of tobacco and alcohol. They recommend that people who smoke should be advised to quit and that safe levels of alcohol be promoted. Outdoor workers and people engaging in outdoor leisure activities should be advised to protect their lips from ultraviolet damage..$^{25}$

Two studies have recently been conducted of smoking cessation practices used by NSW dentists. The majority of dentists reported that they ascertained their patients' smoking status at least some of the time. ${ }^{26,27}$ Dentists said that they told their patients about the oral and general health effects of smoking and advised them to quit or cut down. ${ }^{26,27}$

\section{Secondary prevention}

Intervention and excision of leukoplakias and erythroplakias, combined with elimination of risk factors associated with their development, reduces the incidence of oral cancer. ${ }^{11}$ Opportunistic screening for oral cancer by oral examination can be carried out during patients' regular visits to their doctor or dentist. All that is needed is a good light and chair (a dental unit is ideal) and a simple systematic examination of all sites in the mouth. Patients with positive findings should be referred to a specialist for a definitive diagnosis, biopsy and further management.

\section{Oral cancer screening}

Both the Canadian Task Force on the Periodic Health Examination, ${ }^{28}$ and the US Preventive Services Task Force, ${ }^{29}$ report that there is insufficient evidence to recommend for or against routine screening of asymptomatic people for oral cancer. Likewise, in Australia, the NH\&MRC does not advocate routine oral screening of asymptomatic people, observing that there is no evidence that early detection lowers mortality rates from oral cancer. Both the Canadian and US Task Forces recommend implementing smoking cessation strategies and the US task forces also recommends limiting alcohol consumption. ${ }^{28,29}$ The Canadian Task Force also suggested that annual oral examinations should be considered for people over 60 years of age who have risk factors for oral cancer. ${ }^{28}$ The American Cancer Society recommends a checkup for oral cancer every three years, and the National Cancer Institute and National Institute of Dental Research in the United States both support efforts for early detection through routine dental examinations.

A large randomised controlled trial of screening being conducted in India has shown promising results after two years. ${ }^{30}$ However, the prevalence of oral cancer in India is up to four times higher than in other countries.
Consequently, the results may not be generalisable to Australia.

More information describing the prevalence of risk factors in the community is needed. As well, research to demonstrate the effectiveness of primary prevention strategies and the reliability, validity and responsiveness of effective screening or case-finding methods is required. Further laboratory research at the level of gene mutational analysis could assist the fundamental understanding of the process of oral carcinogenesis.

\section{CONCLUSION}

Oral cancers are a potentially preventable cause of morbidity and mortality. The major risk factors, tobacco and alcohol consumption, and sunlight for lip cancer, are all also major risk factors for other common diseases. Oral health professionals should engage with other health professionals to identify and implement effective strategies to reduce the prevalence of these risk factors. As well, oral health professionals should be actively involved in effective risk-reducing strategies for their patients and in providing systematic oral examinations, especially for those at greatest risk of developing oral cancer.

\section{REFERENCES}

1. Coates M, Armstrong B. Cancer in New South Wales: Incidence and Mortality 1995. Sydney: NSW Central Cancer Registry Cancer Control Information Centre, NSW Cancer Council, 1998.

2. McCredie M, Coates MS, Day P, Bell JC. Changes in cancer incidence and mortality in New South Wales. Med J Aust 1995; 163: 520-523.

3. MacFarlane G, McCredie M, Coates M. Patterns of oral and pharyngeal cancer: Incidence in New South Wales, Australia. J Oral Pathol Med 1994; 23: 241-245.

4. MacFarlane G, Sharp L, Porter S, Franceschi S. Trends in survival from cancer of the oral cavity and pharynx in Scotland: A clue to why the disease is becoming more common. Br J Cancer 1996; 73: 805-808.

5. Smith D, Taylor R, Coates M. Socio-economic differentials in urban New South Wales. Aust NZ J Pub Health 1996; 20 : 129-137.

6. Survival from Cancer in New South Wales: 1980 to 1995. Sydney: NSW Central Cancer Registry Cancer Control Information Centre, NSW Cancer Council, 1999.

7. Epidemiology of cancer in South Australia: Incidence, mortality and survival, 1977 to 1996; Incidence and Mortality, 1996. Adelaide: South Australian Cancer Registry, 1997.

8. Blot W, McLaughlin JK, Winn DM, et al. Smoking and drinking in relation to oral and pharyngeal cancer. Cancer Res 1988; 48: 3282-3287.

9. Pindborg J, Daftary DK, Gupta P, et al. Public Health Aspects of Oral Cancer. In: Johnson NW, ed. Risk Markers for Oral Diseases. Cambridge University Press; 1991: 338388.

10. Einhorn J, Wersall J. Incidence of oral carcinoma in patients with leukoplakia of the oral mucosa. Cancer 1967: 20: 21892193. 
11. Banoczy J. Follow-up studies in oral leukoplakia. J MaxFac Surg 1977; 5: 69-75.

12. Scully C. Clinical diagnostic methods for the detection of premalignant and early malignant lesions. Community Dental Health 1993: 10 (Suppl. 1): 43-52.

13. Barnard, NA, Scully C, Eveson J Jnr, et al. Oral cancer development in patients with oral lichen planus. J Oral Pathol Med 1993; 22: 421-424.

14. Odell EW, Morgan PR. Biopsy pathology of the oral tissues. London, Melbourne: Chapman and Hall Medical, 1998: 53.

15. Murti PR, Bhonsle RB, Pindborg JJ, Gupta PC, Mehta FS. Malignant transformation rate in oral submucous fibrosis over a 17 year period. Community Dental Health Oral Epidemiol 1985; 13: 340-341.

16. Daftary D, Murti P, Bhonsle R, Gupta P, Mehta F, Pindborg JJ. Risk factors and risk markers for oral cancer in high incidence areas of the world. In: Risk markers for oral diseases, vol 2, Oral Cancer. Cambridge University Press, 1991: 29-62.

17. Henderson BE, Aiken GH. Cancer in Papua New Guinea. Monograph 53. Bethesda: National Cancer Institute, 1979; 67-72.

18. Steinmetz KA, Potter, JD. Vegetables, fruit and cancer. I: Epidemology. Cancer Causes Control 1991; 2: 325-357.

19. La Vecchia C, Franceschi S, Levi F, Lucchini F, Negri E. Diet and human oral carcinoma in Europe. Eur J Cancer B. Oral Oncol 1993; 29B: 17-22.

20. Stjernsward J. Cost benefit in Sri Lanka. Fact sheet 14. Oral cancer. London: Cancer Research Campaign, 1990.

21. Franceschi S, Talamini R, Barra S et al. Smoking and drinking in relation to cancers of the oral cavity, pharynx, larynx and esophagus in Northern Italy. Cancer Res 1990; 50: 65026507.

22. Schottenfeld D et al. Alcohol as a co-factor in the etiology of cancer. Cancer 1979; 43: 1962-1966.

23. Negri E, La Vecchia C, Franceschi G, Tavani A. Attributable risk for oral cancer in Northern Italy. Cancer Epidemiol Biomarkers Prev 1993; 2: 189-193.

24. Gupta PC, Mehta FS, Pindborg JJ et al. Intermediary study for primary prevention of oral cancer among 36,000 Indian tobacco users. Lancet 1986; i : 1235-1238.

25. NHMRC. Guidelines for Preventive Interventions in Primary Health Care, Cardiovascular Disease and Cancer. Canberra: NHMRC, 1996.

26. Rikard-Bell G. Smoking cessation advice in dentistry. MPH treatise, University of Sydney 1998.

27. Clover K, Hazell T, Stanbridge V, Sanson-Fisher R. Dentists' attitudes and practice regarding smoking. Aust Dent J 1999; 44: 46-50.

28. Canadian Task Force on the Periodic Health Examination. Canadian Guide to Clinical Preventive Health Care. Ottawa: Canadian Communication Group, 1994; 838-847.

29. Guide to Clinical Preventive Services. Report of the US Preventive Task Force, 2nd edn, Chapter 16. Screening for oral cancer. Baltimore: Williams and Wilkins, 1996.

30. Trivandrum Oral Cancer Screening Study. Summary of results: process and intermediate outcome measures. IARC, Lyon, France. Abstract, p.15. In: Conference Proceedings of the 6th International Congress on Oral Cancer. UICC Meeting, New Delhi, 1999. Delhi: Macmillan, 1999. it

\section{ORAL HEALTH RESEARCH: CURRENTTRENDS AND FUTURE RESEARCH REQUIREMENTS}

\section{A. John Spencer \\ Professor of Social and Preventive Dentistry \\ Director, Dental Statistics and Research Unit Australian Institute of Health and Welfare \\ University of Adelaide}

Oral health is not included in Australia's identified health priorities. Perhaps the decline in caries in children and the increased tooth retention in adults have led decisionmakers to conclude that the public health issues in dentistry have been largely solved. ${ }^{1}$ However, this is not the case.

Oral diseases and disorders are still among the most prevalent causes of morbidity in our community. Past or present dental caries experience and less severe forms of periodontal diseases are ubiquitous among adults. Collectively, oral diseases and disorders propel the gastrointestinal system to the top of 'cost of illness' calculations. While generic measures do not capture the substantial effect of oral diseases on quality of life, specific measures of oral 'quality of life' show a moderate prevalence of negative effects across a range of physical, social and psychological domains. Dental caries and periodontal diseases are largely preventable, and both are amenable to treatment that restores function. In addition to these prevalent oral diseases, less common oral problems contribute to significant public health problems such as injuries and cancer.

This paper describes the oral health research that is required to better understand the nature and distribution of oral diseases, their aetiology, and the efficacy of interventions. The necessary oral health research can best be organised around specific age cohorts in the community. ${ }^{2,3}$

\section{PRE-SCHOOL CHILDREN}

The oral health of pre-school children has improved considerably over the last four decades. However, three issues warrant further research:

- the prevalence of early childhood caries

- the plateauing of caries experience in the deciduous dentition 